\title{
Deep Drilling at the Dead Sea
}

by Mordechai Stein, Zvi Ben-Avraham, Steve Goldstein, Amotz Agnon, Daniel Ariztegui, Achim Brauer, Gerald Haug, Emi Ito, and Yoshinori Yasuda

doi:doi:10.2204/iodp.sd.11.04.2011

At the lowest point on Earth, the Dead Sea, a unique scientific project, the Dead Sea Deep Drilling Project (DSDDP), is being conducted to establish a late Quaternary paleoenvironmental, tectonic, and seismological archive. Scientific groups from Germany, Israel, Japan, Jordan, Norway, Palestine, Switzerland, and the U.S.A. gathered for the first time on 21 November 2010 to perform scientific drilling at the floor of the deep basin of the Dead Sea (Fig. 1). With current lake level of $423 \mathrm{~m}$ below sea level and water depth of $300 \mathrm{~m}$, coring started at $723 \mathrm{~m}$ below mean sea level. During the first three weeks of drilling 460 meters of sediment cores were recovered. As expected from shallow piston cores and on-land deposits from the lake level highstands, the cores are composed of alternating intervals of marly units and salts (Fig. 2). The sedimentary intervals represent several glacial and interglacial cycles spanning an estimated interval of $\sim 200,000$ years. Two coarse-grained sections imply almost complete dry-out phases of the Paleo-Dead Sea, meaning that twice the lake surface was several hundred meters below present day sea level.

Drilling is being conducted with the Large Lake Drilling Facility (see front cover of this issue) of DOSECC (Drilling Observation and Sampling of the Earth's Continental Crust, Inc.). The upper 30 meters were cored by using a hydraulic

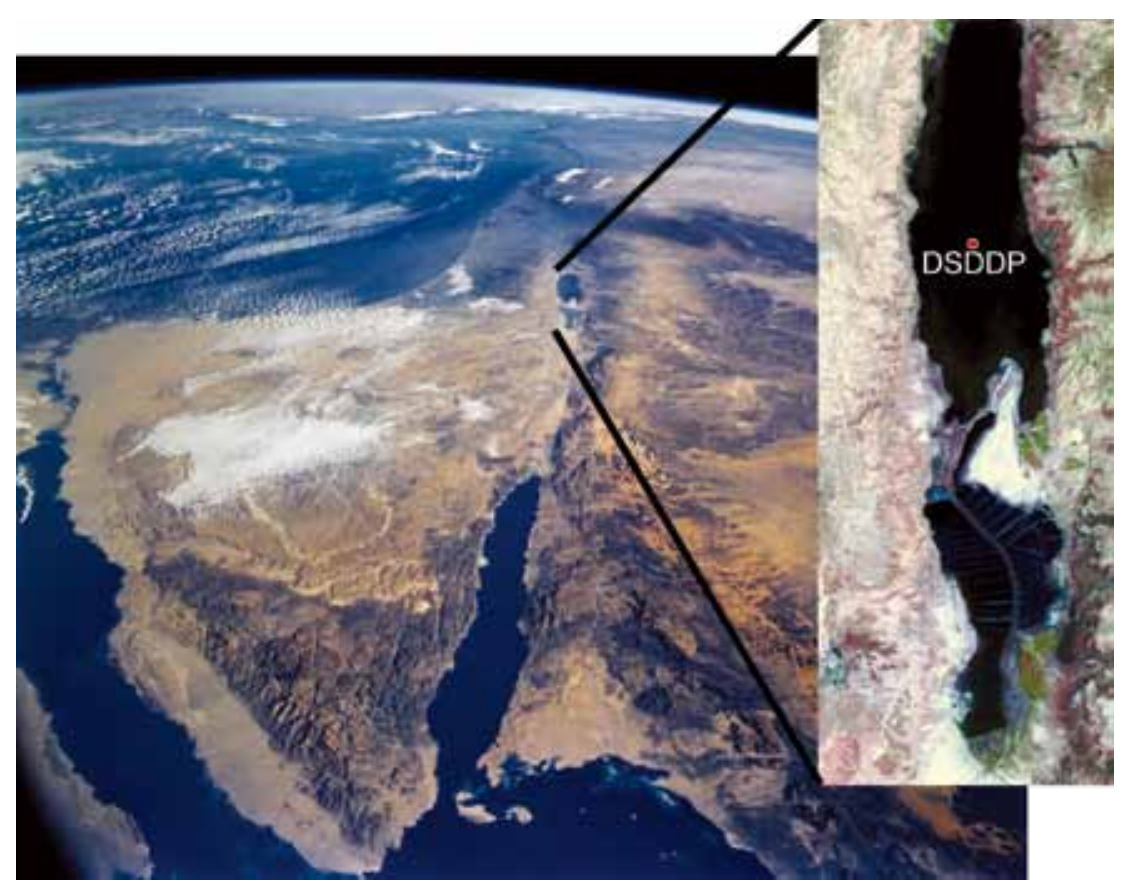

The Dead Sea basin and the location of the ICDP-DSDDP drilling site. piston coring system that is capable of penetrating several salt layers with high core recovery, while the deeper section was retrieved with the extended-nose bit coring tools (Fig. 3).

\section{Why Drill the Dead Sea?}

The Dead Sea Basin (DSB) is located between the Mediterranean and desert climate zones. In the late Neogene the basin was invaded by Mediterranean marine water that formed the Sedom lagoon. The evaporated ingressing seawater led to the deposition of thick sequences of salt and formation of the calcium chloride brine that dominated the subsequent geochemical-limnological evolution of water bodies in the basin. After disconnection of the Sedom lagoon from open sea, the basin was filled with several lakes that captured in their sedimentary filling the hydrological regime of large drainage area of the DSB, reflecting the Levant paleoclimate. The lakes expanded during ice ages and contracted during interglacials. During the last glacial ( 70-14 ka ago) Lake Lisan rose up to $250 \mathrm{~m}$ above the Holocene Dead Sea and extended from south of the modern Dead Sea northward to the Sea of Galilee. This configuration illustrates the dramatic changes in the regional hydrology and lake configuration and reflects global climate conditions. Moreover, the formation of the DSB is associated with the tectonic activity along the Dead Sea Transform Fault (BenAvraham, 1997); thus, its sediments preserve the history of earthquakes (Migowski et al., 2004). The DSB is also the locus of humankind's migration out of Africa, and the home of people from Paleolithic to modern times (Goren-Inbar et al., 2000). Studies of the sedimentary sections exposed on the Dead Sea margins have been applied to issues with global and region-al implications associated with paleoclimate, tectonics, paleoseismology, paleomagnet-ism, and human history (Stein, 2001; Enzel et al., 2006; Waldmann et al., 2010).

The lacustrine sections exposed in the marginal terraces of the modern Dead Sea contain only the sedimentary archives deposited during lake highstands (e.g., the Lisan Formation). The main operational purpose of the DSDDP is to recover long, continuous, high-resolution cores that will provide a com- 


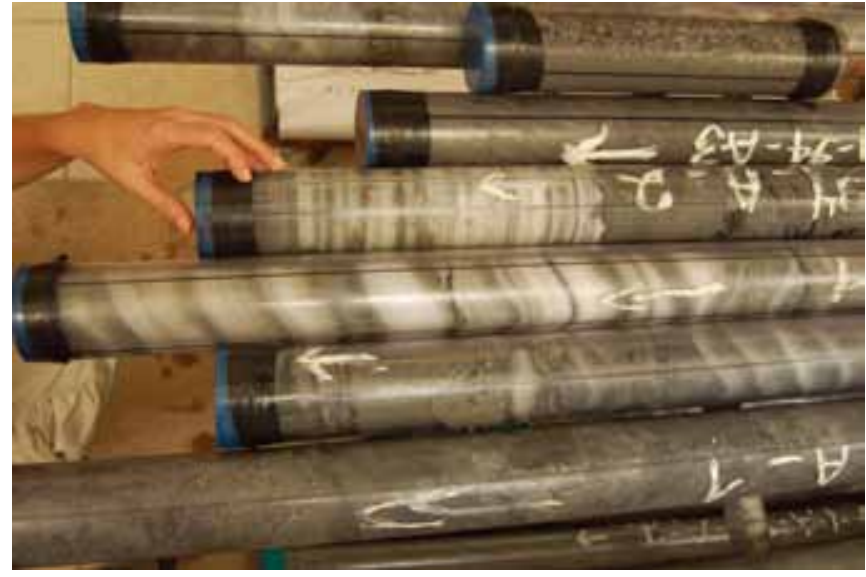

Drill cores in liners recovered at depth around $300 \mathrm{~m}$ below lake floor. From top to bottom the cores show change from gravel (top core) to marls interlaced with fine-grained salt layers (middle cores). This suggests that at that time the shore was very close to the drilling site, and the wavy salt patterns were interpreted as a result of salt flow.

plementary record to the sections recovered from the marginal terraces, particularly for time interval of low lake stands when the lake retreated from the marginal terraces. The calcium chloride brine that was produced during the ingression of the Sedom lagoon is poor in bicarbonate and sulfate, and therefore, when freshwater enters the lake, primary aragonite is deposited. The aragonite provides an excellent and unique means to achieve calendar chronology down to a few hundred thousand years. This illustrates a major advantage of the sedimentary archive of the Dead Sea and allows comparison to global records such as ice cores and deep sea cores. Data from core samples will establish a pattern of abrupt hydrological events in the drainage area, and the brine-freshwater relations during the different stages will be explored to evaluate effects of long-term climatic trends versus short-term fluctuations.

The project is performed under the wings and support of the International Continental Scientific Drilling Program (ICDP). The drilling operation is performed by DOSECC.

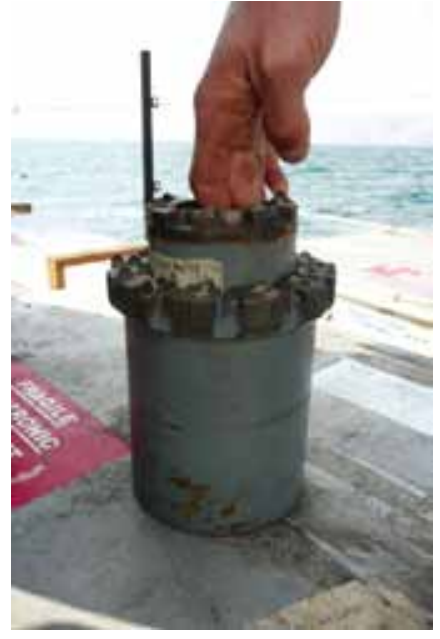

Figure 3. Extended-nose coring tool with outer and inner core bit. Most of the cores were retrieved with this tool.

\section{References}

Ben-Avraham, Z., 1997. Geophysical framework of the Dead Sea: structure and tectonic. In Niemi, T.M., Ben-Avraham, Z., and Gat, J.R. (Eds.), The Dead Sea: The Lake and Its Settings: New York (Oxford University Press), Oxford Monographs on Geology and Geophysics, 36:22-35.
Enzel. Y., Agnon A. and Stein M. 2006. New Frontiers in Dead Sea Paleoenvironmental Research, GSA Spec. paper 401: Boulder, $\mathrm{CO}$ (The Geological Society of America).

Goren-Inbar, N., Feibel, C.S., Verosub, K.L., Melamed, Y., Kislev, M., Tchernov, E., and Saragusti, I., 2000. Pleistocene milestones on the out-of-Africa corridor at Gesher Benot Ya'aqov, Israel. Science, 89:944-947.

Migowski, C., Agnon, A., Bookman, R., Negendank, J.F.W., and Stein, M., 2004. Recurrence pattern of Holocene earthquakes along the Dead Sea transform revealed by varve-counting and radiocarbon dating of lacustrine sediments. Earth Planet. Sci. Lett., 222:301-314.

Stein, M., 2001. The history of Neogene-Quaternary water bodies in the Dead Sea Basin. J. of Paleolimnology 26: 271-282.

Waldmann, N., Torfstein, A., and Stein, M., 2010. Northward migration of monsoon activity across the Saharo-Arabian desert belt during the last interglacial: evidence from the Levant. Geology, 38:567-570.

\section{Authors}

Mordechai Stein, Geological Survey of Israel, 30 Malkhe Israel St. Jerusalem, 95501, Israel, e-mail: motistein@gsi. gov.il.

Zvi Ben-Avraham, Department of Geological Sciences, Louis Ahrens Building, Library Road, University of Cape Town, Rondebosch, 7700, Republic of South Africa.

Steve Goldstein, Lamont-Doherty Earth Observatory, 213 Comer, 61 Route 9W - P.O. Box, 1000 Palisades, NY 109648000, U.S.A.

Amotz Agnon, Institute of Earth Sciences, Hebrew University of Jerusalem, Edmond J. Safra campus, Givat Ram, 91904, Jerusalem.

Daniel Ariztegui, Department of Geology and Paleontology, University of Geneva, 13, Rue des Maraîchers, CH-1205 Genève, Switzerland.

Achim Brauer, Helmholtz Centre Potsdam, GFZ German Research Centre for Geosciences, Section 5.2, Climate Dynamics and Landscape Evolution, Telegrafenberg, C 323 D-14473 Potsdam, Germany.

Gerald Haug, ETH Zürich, Geologisches Institut NO G 51.1, Sonneggstrasse 5, 8092 Zürich, Switzerland.

Emi Ito, Geology and Geophysics, Room 108, PillsH 0211, 310 Pillsbury Drive SE, Minneapolis, MN 55455, U.S.A.

Yoshinori Yasuda, International Research Center for Japanese Studies, 3-2 Oeyama-cho, Goryo, Nishikyo-ku, Kyoto 610-1192, Japan.

\section{Related Web Links}

http://deadsea.icdp-online.org

http://www.dosecc.org

\section{Figure Credits}

Fig. 1: The National Aeronautics and Space Administration, (NASA)

Fig. 2: Michael Lazar, Department of Marine Geosciences, University of Haifa, Israel

Fig. 3: Uli Harms, ICDP, GFZ Potsdam, Germany 